\title{
An infant with an extremely rare cobalamin disorder: Methionine synthase deficiency and importance of early diagnosis and treatment
}

\author{
Çiğdem Seher Kasapkara ${ }^{1,5}$, Ebru Yılmaz-Keskin², Ferda Özbay-Hoşnut ${ }^{3}$, Meltem Akçaboy ${ }^{4}$, \\ Emine Polat ${ }^{4}$, Asburçe Olgaç ${ }^{1}$, Pelin Zorlu ${ }^{4}$ \\ Departments of ${ }^{1}$ Pediatric Metabolism and Nutrition, ${ }^{3}$ Pediatric Gastroenterology and ${ }^{4}$ Clinic of Pediatrics, Dr. Sami Ulus \\ Maternity and Children's Training and Research Hospital, Ankara; ${ }^{2}$ Department of Pediatric Hematology and Oncology, \\ Süleyman Demirel University School of Medicine, Isparta; ${ }^{5}$ Department of Pediatrics, Ylldırm Beyazıt University Faculty \\ of Medicine, Ankara, Turkey. E-mail: cskasapkara@gmail.com
}

Received: 26th December 2017, Accepted: 27th January 2018

SUMMARY: Kasapkara ÇS, Yılmaz-Keskin E, Özbay-Hoşnut F, Akçaboy M, Polat E, Olgaç A, Zorlu P. An infant with an extremely rare cobalamin disorder: Methionine synthase deficiency and importance of early diagnosis and treatment. Turk J Pediatr 2019; 61: 282-285.

Functional methionine synthase deficiency can be separated into two classes, cobalamin (Cbl) deficiency type E (CblE) and type G (CblG), which are the result of mutations that affect methionine synthase reductase or methionine synthase, respectively. Deficiency of methionine synthase activity may result in megaloblastic anemia without methylmalonic aciduria and neuromuscular abnormality of varying severity. Delayed milestones, ataxia, cerebral atrophy, muscular hypotonia, neonatal seizures, and blindness have been reported as the associated clinical findings. Early diagnosis and treatment are crucial for a more favorable diagnosis of the affected cases. Herein we report a three-month-old boy with CblG disease who presented with failure to thrive, chronic diarrhea, feeding intolerance, oral ulcers, microcephaly and hypotonia, and showed a dramatic response to treatment. In the first few months of life, megaloblastic anemia accompanied by apparent neurological involvement should direct physicians to order examinations like measurement of total homocysteine and methylmalonic acid levels to detect possible forms of inherited $\mathrm{Cbl}$ intracellular metabolism disorders.

Key words: cobalamin, homocysteine, methionine, megaloblastic anemia.

Methionine synthase (MS) is a cobalamindependent enzyme that catalyzes the methylation of homocysteine to methionine and requires the vitamin B12 derivative methylcobalamin (MeCbl) as a cofactor and 5-methyltetrahydrofolate as methyl donor. Functional MS deficiency can be separated into two classes, cobalamin ( $\mathrm{Cbl}$ ) deficiency type $\mathrm{E}$ (CblE) and type G (CblG), which are the result of mutations that affect methionine synthase reductase or MS, respectively. ${ }^{1,2}$

$\mathrm{CblG}$ disorder is an autosomal recessive disease caused by mutations in the MTR gene on chromosome1q43, which encodes MS leading to impairment of the remethylation of homocysteine to methionine. Deficiency of MS activity has been shown to result in the biochemical phenotypes of hyperhomocysteinemia, homocystinuria, hypomethioninemia, and megaloblastic anemia without methylmalonic aciduria. Patients show a range of clinical symptoms, including delayed milestones, ataxia, cerebral atrophy, muscular hypotonia, neonatal seizures, and blindness. ${ }^{3}$

Herein we report a three-month-old boy with CblG disease who presented with failure to thrive, chronic diarrhea, feeding intolerance, oral ulcers, microcephaly and hypotonia.

\section{Case Report}

A three-month-old male infant who was born at term to consanguineous healthy Turkish parents came to our attention. The pregnancy 
was uneventful and the baby was born by normal vaginal delivery at 37 weeks gestation, with a birth weight of $2,500 \mathrm{~g}$ and head circumference of $33 \mathrm{~cm}$. He was breastfed and the early neonatal course was uneventful until the end of the second week of life when he started to present poor sucking, oral ulcers, diarrhea and feeding difficulties. The case initially received antibiotic and fluid therapy in Neonatal Intensive Care Unit.

At the age of 3 months, he had no social smile, and head lag and axial hypotonia were noted. His head circumference and weight were $33.5 \mathrm{~cm}$ and $3500 \mathrm{~g}$, both being below the $3^{\text {rd }}$ percentile for age. Further examinations showed macrocytic anemia [hemoglobin $7.2 \mathrm{~g} /$ $\mathrm{dl}$; mean corpuscular volume $119 \mathrm{fL}$ (normal range: $74-108 \mathrm{fL}$ )], normal serum vitamin $\mathrm{B} 12$ and folate and elevated lactate dehydrogenase levels. Bone marrow examination revealed megaloblastic changes.

Microcephaly, megaloblastic anemia, neurological symptoms in the presence of failure to thrive and feeding difficulties raised the suspicion of a remethylation disorder. Homocysteine in the urine of $459 \mu \mathrm{mol} / \mathrm{g}$ creatinine (normal $<8.8 \mu \mathrm{mol} / \mathrm{g}$ ) in a metabolic screen prompted further testing for metabolites indicative of defects in cobalamin metabolism.
Extensive biochemical analyses revealed a plasma total homocysteine level of $>100$ $\mu \mathrm{mol} / \mathrm{L}$ (normal: 5-13 $\mu \mathrm{mol} / \mathrm{L}$ ), analysis of plasma amino acid profile documented low levels of methionine $(8 \mu \mathrm{mol} / \mathrm{L}$; normal: $9-42 \mu \mathrm{mol} / \mathrm{L}$ ) and absence of methylmalonic acid.

Initial treatment including intramuscular hydroxycobalamin $1 \mathrm{mg} /$ day, betaine 250 $\mathrm{mg} / \mathrm{kg} / \mathrm{day}$, and folinic acid $15 \mathrm{mg}$ three times a week, was commenced. The plasma homocysteine concentration reached normal levels in 15 days, after which the patient was switched to maintenance treatment consisting of intramuscular hydroxycobalamin $1 \mathrm{mg}$ two times per week, betaine $100 \mathrm{mg} / \mathrm{kg} /$ day and folinic acid $15 \mathrm{mg}$ three times a week, without protein restriction. Methionine was not supplemented because methionine levels increased spontaneously. In the followup, we decreased betaine dosage according to methionine levels to $100 \mathrm{mg} / \mathrm{kg} /$ day. In addition, when the patient was receiving betaine at the dosage of $250 \mathrm{mg} / \mathrm{kg} / \mathrm{day}$, his liver enzymes were found to be elevated [aspartate aminotransferase (AST) $258 \mathrm{U} / \mathrm{L}$; alanine aminotransferase (ALT) $133 \mathrm{U} / \mathrm{L}$ (normal range: $0-40 \mathrm{U} / \mathrm{L})$ ]. When betaine dosage was lowered to $100 \mathrm{mg} / \mathrm{kg} /$ day, the liver enzyme

Table I. Clinical and Laboratory Features of the Case at Admission and After Treatment Initiation.

\begin{tabular}{lcc}
\hline Clinical and laboratory features & Before treatment & After treatment \\
\hline Patient's age & 3 months & 9 months \\
Vitamin B12 & Normal & \\
Folate & Normal & 7.4 \\
Total homocysteine, $\mu$ mol/L (normal: 13-5) & $>100$ & 37 \\
Methionine, $\mu$ mol/L (normal: 9-42) & 8 & 0 \\
Methylmalonic acid & 0 & 11.2 \\
Hemoglobin, g/dl & 7.2 & 80 \\
Mean corpuscular volume, fL & 117 & \\
(normal: 74-108) & Normal & He had head control, \\
Cranial MRI & Microcephalic and hypotonic & could sit unsupported \\
Neurological development & 33.5 & 43 \\
Head circumference, cm & 3,500 & 8,300 \\
Body weight, g & Noad control & \\
\hline
\end{tabular}

Treatment was initiated at the age of 3.5 months; and was composed of parenteral OH-cobalamin ( $1 \mathrm{mg}$ IM for 5 days, $1 \mathrm{mg}$ IM 2 times/week), betaine $(250 \mathrm{mg} / \mathrm{kg} /$ day; the dose was decreased to $100 \mathrm{mg} / \mathrm{kg} / \mathrm{day}$ after $1.5 \mathrm{months}$ due increased methionine levels and elevation of liver enzymes), and folinic acid (15 mg 3 times/week). 
levels declined to normal range. Notably, all hematological parameters normalized in the follow-up examinations (Table I).

Molecular genetic investigation identified the mutation c.3518C $>\mathrm{T}$ in exon 31 of the MTR gene in homozygous state. The missense mutation predicts an amino acid change from proline to leucine at position 1173 [p.(Pro1173Leu)] in the mature protein which has previously been reported. ${ }^{4}$ This result was consistent with a diagnosis of CblG deficiency.

The case showed marked clinical and biochemical response to treatment. It is most probably related to early time of therapy initiation. Ophthalmological investigations at 3 and 9 months showed that he could fix and follow with either eye without any evidence of retinopathy. Visual evoked potentials responses were in the normal range. Brain magnetic resonance imaging (MRI) was normal. At the latest follow-up at 9 months, his head circumference reached $43 \mathrm{~cm}$, he gained weight and reached $8300 \mathrm{~g}$, could sit unsupported and had no evidence of any motor delay.

An informed consent was received from the family.

\section{Discussion}

Inherited diseases of $\mathrm{Cbl}$ intracellular metabolism are very rare disorders, Cbl C disease (CblC) being the most common one. ${ }^{5}$ They affect the synthesis or utilization of its two metabolically active forms, methyl- (MeCbl) and adenosylcobalamin (AdoCbl). These errors can be classified as follows: 1) combined methylmalonic acidemia and homocystinuria affecting both AdoCbl and $\mathrm{MeCbl}$ due to defects in lysosomal $\mathrm{Cbl}$ release ( $\mathrm{CblF}$ and $\mathrm{CblJ}$ ) or cytosolic $\mathrm{Cbl}$ conversion (CblC) or targeting (CblD); 2) homocystinuria with low/normal methionine levels: due to improper targeting of Cbl to MS (CblD variant 1), dysfunction of MS reactivation (CblE) or dysfunction of MS itself (CblG); 3) isolated methylmalonic acidemia: due to improper gating (CblA), production (CblB), or targeting (CblD variant 2) of AdoCbl to methylmalonyl-CoA mutase (mut). MS catalyzes the methylation of homocysteine to methionine and requires the vitamin B12 derivative, $\mathrm{MeCbl}$, as a cofactor. ${ }^{2-6}$

Methionine synthase deficiency, if not treated properly, can lead to hematological, neurological, cardiovascular, ocular and renal complications. Elevated levels of plasma homocysteine, low levels of serum methionine and normal urine methylmalonic acid levels are the biochemical hallmarks of the disease. Most patients are symptomatic in the first year of life, but isolated cases with later onset have also been reported ${ }^{3}$. Blindness and retinopathy have also been described. Homocysteine may induce retinal microvascular damage and direct cytotoxic effect on the ganglion cell layer. ${ }^{7,8}$ Ophthalmologic examination was normal in our patient with no evidence of retinopathy. It could be related to early diagnosis and treatment.

The patient presented here with the homozygous c.3518C $>$ G mutation share the same mutation previously reported by Komulainen-Ebrahim et al. ${ }^{9}$ They described a patient diagnosed at the age of 2 years with severe megaloblastic anemia, developmental delay, severe microcephaly and drug resistant seizures associated with hyperhomocysteinemia and hypomethioninemia. We suggested that in case of treatment delay, the clinical course and developmental outcome in our patient would not be excellent.

In patients with the CblG disorder, biochemical abnormalities often respond markedly to therapy, whereas the neurological deficits usually resolve more slowly and incompletely. The mainstay of treatment includes high-dose intramuscular hydroxycobalamin, which can lower serum homocysteine levels and increase serum methionine levels. Betaine can also be used to increase remethylation of homocysteine to methionine. ${ }^{4,6-9}$ We started betaine at a dosage of $250 \mathrm{mg} / \mathrm{kg} /$ day which resulted in an increase in methionine levels, and decreased the dosage according to methionine levels to 100 $\mathrm{mg} / \mathrm{kg} /$ day. We also observed a rapid resolution of the metabolic abnormalities and complete resolution of macrocytic anemia.

The presentation in our patient is towards the severe end of the spectrum of neurological dysfunction. His clinical course demonstrated the potential for neurological recovery with early treatment. In conclusion, in the presence of megaloblastic anemia and neurological findings in infants within the first few months of life, physicians should consider possible forms of inherited disorders of $\mathrm{Cbl}$ intracellular 
metabolism as the underlying cause, and order certain examinations, such as the measurement of total homocysteine and methylmalonic acid levels. The significance of early diagnosis and treatment on the clinical outcome of the patients with methionine synthase deficiency should always be kept in mind.

\section{Acknowledgements}

We thank Prof. Matthias Baumgartner at University Children's Hospital Zürich for the genetic analysis of the case.

\section{REFERENCES}

1. Vaisbich MH, Braga A, Gabrielle M, Bueno C, Piazzon F, Kok F. Thrombotic microangiopathy caused by methionine synthase deficiency: Diagnosis and treatment pitfalls. Pediatr Nephrol 2017; 32: 1089-1092.

2. Huemer $M$, Bürer $C$, Ješina $P$, et al. Clinical onset and course, response to treatment and outcome in 24 patients with the cblE or cblG remethylation defect complemented by genetic and in vitro enzyme study data. J Inherit Metab Dis 2015; 38: 957-967.
3. Outteryck O, de Sèze J, Stojkovic T, et al. Methionine synthase deficiency: A rare cause of adult-onset leukoencephalopathy. Neurology 2012; 79: 386-388.

4. Gulati S, Baker P, Li YN, et al. Defects in human methionine synthase in cblG patients. Human Mol Genet 1996; 5: 1859-1865.

5. Wu S, Gonzalez-Gomez I, Coates T, Yano S Cobalamin $\mathrm{C}$ disease presenting with hemophagocytic lymphohistiocytosis. Pediatr Hematol Oncol 2005; 22: 717-721

6. Watkins D, Rosenblatt DS. Update and new concepts in vitamin responsive disorders of folate transport and metabolism. J Inherit Metab Dis 2012; 35: 665-670.

7. Elmore $\mathrm{CL}, \mathrm{Wu} \mathrm{X}$, Leclerc $\mathrm{D}$, et al. Metabolic derangement of methionine and folate metabolism in mice deficient in methionine synthase reductase. Mol Genet Metab 2007; 91: 85-97.

8. Poloschek CM, Fowler B, Unsold R, Lorenz B. Disturbed visual system function in methionine synthase deficiency. Graefes Arch Clin Exp Ophthalmol 2005; 243: 497-500.

9. Komulainen-Ebrahim J, Saastamoinen E, Rahikkala $\mathrm{E}$, et al. Intractable epilepsy due to MTR deficiency: Importance of homocysteine analysis. Neuropediatrics 2017; 48: 467-472. 